\title{
Effects of a single insulin injection on approaches to food and on the temporal pattern of feeding*
}

\author{
D. A. BOOTH and J. F. PAIN \\ University of Sussex, Brighton, England $\dagger$
}

Naive rats raise a panel in approaching food more often after their first insulin injection than after a control injection. At the same time there is a reduced incidence of long pauses in feeding under the influence of injected insulin. Also, the size of the first feeding bout after injection and its ratio to the delay before the next feeding bout both increase. This suggests that insulin elicits hunger by attenuating satiety signals.

The present study was undertaken to determine whether a single injection of regular insulin would facilitate acquisition of approach to food in a situation with which the rat was unfamiliar. If it did, this would be additional evidence that insulin on first injection induces a state in the rat similar to normal hunger (Booth \& Brookover, 1968). The intensity of hunger induced was expected to be low. Also, some concurrent general behavioral depression was anticipated (Lovett \& Booth. 1970). So a continuously adjusting ratio schedule was used to maximize incentive for the occasional approach while minimizing the chance of satiating the rapidly performing rat. Because performance over a 4-h session was not uniform in rate, in addition to testing for facilitated approach and feeding behavior overall, the pattern of pauses in feeding was also analyzed.

\section{METHOD}

Twenty-four male albino rats $(250-450 \mathrm{~g})$ were given $50-\mathrm{mg}$ automatic feeder pellets (MRC diet 4IB) in their home cages for 2 days before the experiment. The rats were maintained on an 8 a.m. -10 p.m. bright-phase lighting cycle with free access to water and chow pellets (41B). At 10 a.m. on an experimental day, the rat was injected subcutaneously with $0.25 \mathrm{ml} / \mathrm{kg}$ of either water or neutral soluble insulin (40 units $/ \mathrm{ml}, \mathrm{BDH}$ ) $5 \mathrm{~min}$ before being placed in the test box. Twelve of the rats were given insulin on their first day in the box; the other 12 had the control injection first. A second test, under the other injection condition, followed after $2 \cdot 3$ days.

\footnotetext{
*The authors were supported by a grant from the Medical Research Council, U.K. The computer facilities were made available through a grant from the Scientific Research Council. We are grateful to Mr. J. Francis for writing the experiment control program and to Messrs. G. Russell and D. Kemp for running animals. BDH (Research) kindly gave us insulin.

+ Mailing address: Laboratory of Experimental Psychology, University of Sussex, Brighton BN1 9QY, England.
}

The test box contained a top-hinged aluminum panel $(8 \mathrm{~cm}$ high, $4 \mathrm{~cm}$ wide $)$ reaching to floor level. Behind it was a tray into which a feeder delivered pellets. A calibrated water tube was placed $10 \mathrm{~cm}$ to the side of the panel, with the spout level with the panel top. Raising of the panel and its lowering under its own weight were detected by a photoelectric sensor. One pellet was in the tray behind the closed Raising the panel after it had been lowered sent a pulse to a computer that was programmed to emit a pulse to operate the feeder solenoid according to an adjusting ratio schedule. This schedule had five states: CRF, FR2, FR4, FR8, and VR 16 (Range 1-32, random sequence). The session always began in the CRF state. Delivery of a pellet in any state increased the ratio to the next state, up to VR 16. Failure to lower and raise the panel within $15 \mathrm{sec}$ of the previous panel raise decreased the ratio by one state and also gave a pellet for the next panel raise. Panel raisings, feeder actuations, and states of the ratio schedule were logged and printed out at the end of a session for intervals of 1 and 10 min over the $4 \mathrm{~h}$ for which the rat was in the box. Water intake was read at the end of the session and pellets remaining in the tray were counted.

\section{RESULTS}

Approaches to food during the whole 4-h session after injection, as indicated by the number of times the panel in front of the food tray was pushed up by the rat, were significantly more frequent after insulin than in the control condition, whether the session under the influence of panel when the rat was placed in the box.

the insulin injection was the first or the second in the box (Table 1). Also the adjusting schedule was most often at a higher ratio of reinforcement after insulin, reflecting the higher approach rate. The number of food pellets delivered, minus pellets remaining at the end of the session on the minority of occasions when not all pellets were eaten, was also greater after insulin, although this was only noticeably the case if the first acquaintance with the box was after the control injection. Intake from the water tube over the $4 \mathrm{~h}$ was also reliably increased.

When cumulations of behavior over 10-min intervals were examined, the earliest time at which the greater rate of panel raising in the insulin condition was significant $(p<0.02$, correlated 1$)$ was at 10-20 min. The rate increased further at 20-30 min and then diminished slightly. It was higher in the first eight periods of $10 \mathrm{~min}$ than in any subsequent $10-\mathrm{min}$ period. The first important increase in pellet delivery rate occurred at 20-30 $\mathrm{min}$. This rate increment then remained through the 200th min of the session. These latencies and the persistence of augmented feeding rate are consistent with those observed in experiments on the effects of a single insulin injection on intake of $1.2 \mathrm{~g}$ maintenance chow pellets in the home cage (Booth \& Brookover, 1968).

Intervals greater than 1 min between pellet deliveries often occurred. The frequency histogram of interpellet intervals down to 1 -min interval durations (the resolution of the record) showed a fairly smooth $\mathbf{J}$-distribution with a high frequency of short intervals. Fig. 1 shows that approximations to Poisson distributions existed in both insulin and control conditions. (Order of injection had negligible effects on the functions.) Interpellet intervals greater than a given duration are plotted on a logarithmic scale against time. Over the duration range within which criteria of meal ending are usually chosen $(10-40 \mathrm{~min})$, the functions were linear. Discontinuities occurred only at less than $1 \mathrm{~min}$, at 5 or $7 \mathrm{~min}$, and perhaps at around 40 or $65 \mathrm{~min}$ (for insulin and control conditions, respectively).

Table 2 uses the meal-end criteria of 6 or $60 \mathrm{~min}$ without eating, which are indicated

Table 1

Food Approaches, Feeding, and Drinking After Insulin or Control Injection

\begin{tabular}{|c|c|c|c|c|c|c|}
\hline & \multicolumn{3}{|c|}{ Insulin First } & \multicolumn{3}{|c|}{ Insulin Second } \\
\hline & Insulin & Control & $\mathrm{p}$ & Insulin & Control & $\mathrm{p}$ \\
\hline Panel raisings & $358 \pm 297$ & $230 \pm 228$ & $<0.05$ & $375 \pm 343$ & $184 \pm 104$ & $<0.05$ \\
\hline Modal schedule state & $3.9 \pm 0.5$ & $3.0 \pm 0.5$ & $<0.1$ & $3.6 \pm 0.4$ & $2.5 \pm 0.9$ & $<0.05$ \\
\hline Pellets eaten & $76.1 \pm 44.7$ & $57.4 \pm 42.4$ & $<0.1$ & $73.6 \pm 42.4$ & $39.3 \pm 32.4$ & $<0.01$ \\
\hline Water intake (ml) & $7.7 \pm 2.7$ & $3.3 \pm 2.9$ & $<0.01$ & $8.7 \pm 3.8$ & $3.8 \pm 3.0$ & $<0.02$ \\
\hline
\end{tabular}

Means \pm standard deviations. Two-tailed $p$ values for correlated $t$ tests. 
Table 2

Size and Satiating Power of First Feeding Bout

\begin{tabular}{|c|c|c|c|c|c|c|c|}
\hline & & \multicolumn{3}{|c|}{$\begin{array}{c}\text { Size of Bout } \\
\text { (Number of Pellets) }\end{array}$} & \multicolumn{3}{|c|}{$\begin{array}{c}\text { Utilization Coefficient } \\
\text { (Pellets/Minute) }\end{array}$} \\
\hline & & Insulin & Control & $\mathrm{p}$ & Insulin & Control & $\mathrm{p}$ \\
\hline \multirow{2}{*}{$\begin{array}{l}\text { Criterion } \\
\text { of End } \\
\text { of a Bout }\end{array}$} & $6 \mathrm{~min}$ & $48.0 \pm 20.4$ & $20.2 \pm 11.9$ & $<0.001$ & $3.82 \pm 2.48$ & $2.22 \pm 1.72$ & $<0.01$ \\
\hline & $60 \mathrm{~min}$ & $61.7 \pm 29.3$ & $39.5 \pm 16.0$ & $<0.05$ & $0.93 \pm 0.35$ & $0.52 \pm 0.24$ & $<0.1$ \\
\hline
\end{tabular}

as appropriate by Fig. 1. The first feeding bout of the session persisted through a greater number of pellets in the insulin condition. Also, the ratio of the number of pellets in that first bout to the time between the end of the bout and the beginning of the next bout-a "utilization coefficient"-was increased after insulin. That is, the satiating effect of food did not last as long as under the control condition. No significant differences were obtained for the second and subsequent feeding bouts of a session, which generally were much smaller in size and in utilization coefficient; however, the means for both measures were larger in the insulin condition.

\section{DISCUSSION}

Food Approach

The raising of the panel in front of the food tray was necessary for the rat to gain access to the food pellets in the tray. Also, the delivery of additional pellets was contingent on panel raisings. However, this does not necessarily imply that all or any panel raising was instrumental behavior from the rat's point of view. On the contrary, it is likely that panel raising in the present apparatus, rather than being an

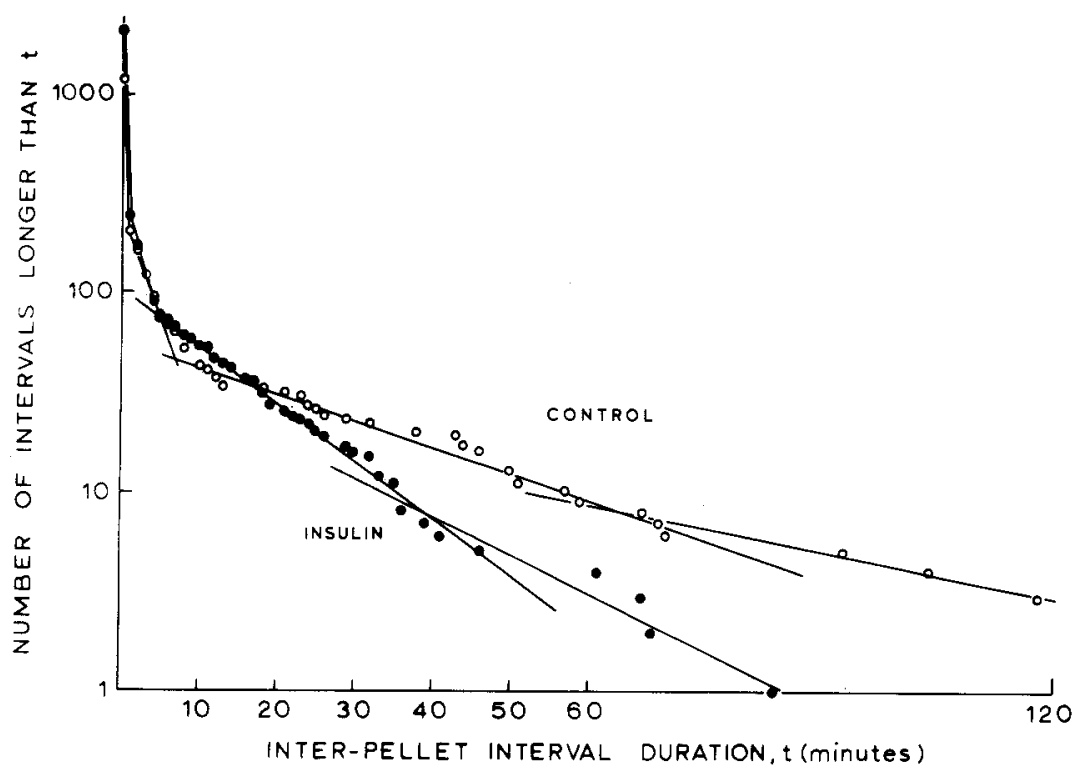

Fig. 1. Interpellet interval frequency distribution. Pauses between pellet idiveries which are longer than a given time are plotted on a logarithmic scale against time. Closed circles: $240-\mathrm{min}$ sessions immediately preceded by injection of 10 units of insulin per kilogram; open circles: control sessions. required four successive raisings and lowerings of the panel with less than $15 \mathrm{sec}$ between them. Such rapidity and persistence of approach to and retreat from one place is unlikely to appear without the learning of some contingency between the number of discrete approach movements and the delivery of food.

\section{Feeding Pattern}

Analysis of the temporal distribution of pellet deliveries indicates that the properties of the response system reflecting satiety are represented by a single Poisson distribution over the range of interpellet intervals from about $5-7 \mathrm{~min}$ to about 40-65 min (the exact limits depending on the presence or absence of injected insulin). Apparently different feeding inhibition systems are operative outside these limits, under the conditions of the present experiment. The intuitive notion of a meal must not be applied to feeding patterns by using an arbitrarily chosen criterion of duration of feeding to define the end of the meal, as has been common practice. The meal-end criterion should be chosen for its functional significance, as indicated by the characteristics of the feeding behavior itself, as in Fig. 1. It is not adequate to justify a criterion by physiological analysis or by the demonstration that conclusions do net vary over a wide range of criteria.

The differences between insulin and control conditions in the temporal distribution of pellet deliveries suggest that insulin attenuates inhibition of feeding. The increased size of at least the first feeding bout of an insulin session can be explained by the also observed increased frequency of interpellet intervals less than $1 \mathrm{~min}$ long. That is, more is eaten in the bout because the basal feeding rate is increased. Similarly, the increased utilization coefficients and decreased number of long interpellet intervals (greater that $5.7 \mathrm{~min}$ ) after insulin may also be related: they could reflect abbreviation of the effective action of postingestive satiety signals. On the other hand, it seems, from the appearance of the distributions of interpellet intervals of $1-5 \mathrm{~min}$, that orally induced satiety is affected little, if at all, by insulin. The acceleration of both feeding rate and decay of satiety could arise from the same metabolic effect of insulin; i.e., the development (through overutilization elsewhere) of a deficit of glucose or amino acid substrates in a cell system that inhibits consummatory reactions when adequate amounts of substrate are available to it. In this respect insulin puts the undeprived rat into a metabolic and behavioral state similar to that which develops during moderate food deprivation, after which transiently increased meal sizes and 
decreased intermeal intervals are also seen (Le Magnen \& Tallon, 1968). The present results demonstrate that such attenuation of satiety by insulin does not require repeated experience of the effects of the hormone, which might allow conditioning or instrumental learning (Le Magnen, 1956; Booth, Goodchild, \& Lovett, 1968; Lovett \& Booth, 1970) to contribute to the changes in the observed meal patterns (Le Magnen \& Tallon, 1967). Differences between this last report and the present results may also arise from different effects of injected insulin on daytime and nightime metabolism and feeding (Le Magnen \& Davos, 1969).

\section{REFERENCES}

BOOTH, D. A., \& BROOKOVER, T. Hunger elicited in the rat by a single injection of bovine crystalline insulin. Physiology \& Behavior, 1968, 3, 447-453.

BOOTH, D. A., GOODCHILD, P., \& LOVETT, D. Depression of intake of nutrient by association of its odor with effects of insulin. Psychonomic Science, 1968, 11, 27-28.

LE MAGNEN, J. Le rôle des stimulations olfacto-gustative dans les mecanismes de regulation de la prise alimentaire. Annales de la Nutrition et l'Alimentation, 1956, 10, 153-158.

LE MAGNEN, J., \& DAVOS, M. Le substrat metabolique de la faim. Comptes Rendus de l'Académie des Sciences, 1969, 268, 3107-3110.

LE MAGNEN, J., \& TALlON; S. Effet des administrations d'insuline et de thyroxine sur la fréquence at l'amplitude unitaire des prises d'aliments chez le rat. Comptes Rendus de la Societé de Biologie (Paris), 1967, 161, 1303-1306.

LE MAGNEN, J., \& TALLON, S. L'effect du jeune prealable sur les caracteristiques temporelles de la prise d'aliments chez le rat. Journal de Physiologie (Paris), 1968, 60, 143-154.

LOVETT, D., \& BOOTH, D. A. Four effects of exogenous insulin on food intake. Quarterly Journal of Experimental Psychology, 1970, 22 , in press.

\section{An effect of flavors on strength of conditioned aversions*}

\section{KENNETH F. GREEN and PEGGY ANN CHURCHILL \\ California State College, Long Beach, Calif. 90801}

Attempts to condition aversions to nonpreferred flavors have not been as consistently successful as when preferred flavors were used. To find if the problem is one of method of measurement or if it is a general characteristic in the conditioning of aversions, the present experiment used several measurement procedures to compare aversions formed by rats to one preferred and one nonpreferred flavor. On all measures, whether relative (decreases in intake) or absolute (final amount consumed), aversions for the preferred flavor were greater than for the nonpreferred flavor.

Conditioned aversions to flavors occur when rats sample a flavored substance (CS) and subsequently become ill (US). Most experimentation on the phenomenon has used fluids that are preferred to water as CSs on the assumption that it is harder to condition an aversion to a preferred stimulus than to a nonpreferred stimulus, and thus a more convincing demonstration of an aversion can be obtained if contact with the CS decreases from a high level than if it decreases from a low level.

Results of studies using nonpreferred CSs have not been entirely consistent with one another. With hydrochloric acid or quinine solutions, Garcia, Green, \& McGowan (1969) reported strong conditioned aversions. With grape juice, Green (1969) reported strong aversions, Revusky \& Bedarf (1967) reported weak aversions, and Wittlin \& Brookshire (1968) reported no aversions. The latter pairs of Es tested for aversions by pairing grape juice with milk, a preferred substance, in a two-bottle test and comparing intake of

*This work was supported in part by a grant from the Long Beach California State College Foundation. experimental rats to intake of controls; by contrast, the former Es either used a single-flavor testing procedure or a two-flavor procedure where both flavors were nonpreferred. In the case where a nonpreferred CS was paired with a preferred comparison flavor, a floor effect might have prevented aversions from being shown. Alternatively, the highly sensitive two-bottle test might have emphasized a basic difficulty in conditioning aversions to nonpreferred CSs: Preference value of a CS might be inversely related to strength of conditioned aversions. Since no major theory of learning suggests such a relationship, the variable of CS preferability was examined in a situation where the possible artifact of a floor effect could be accounted for. The present experiment therefore provided direct comparisons between aversions formed to preferred and nonpreferred CSs and measured the aversions with one-flavor and two-flavor test methods.

\section{METHOD}

Ten female albino rats from the Psychology Department breeding colony weighed $200-250 \mathrm{~g}$ at the start of the experiment. They were given 10 days to adjust to a schedule of $20 \mathrm{~min}$ of drinking per day, with tap water given between the hours of 11 and $12 \mathrm{a} . \mathrm{m}$. as part of a maintenance routine that included feeding, handling, and weighing of bottles to the nearest 0.1 g. On Day 11 , a neophobia day, grape juice (Welch's unsweetened) alone was given. Day 12 was a water day. On Day 13 all rats were given a neophobia day with milk (Pet evaporated, mixed with an equal volume of tap water) alone. Day 14 was a water day, Day 15 was a single-flavor pretest day with milk presented alone, Day 16 was a water day, Day 17 was a single-flavor pretest day with grape juice alone, and Day 18 was a water day. On Days 19 and 20, two-bottle pretests were given with grape juice presented on the left-hand side of the rats' cages immediately before milk was presented on the right. Separate sets of glass bottles, rubber stoppers, and metal spouts were used for each fluid, and each rat was assigned its own bottle-stopper-spout combination for each flavor. Fluids were always presented at room temperature. Acquisition began on Day 20 and consisted of five blocks of 3 days: The 1st was a conditioning day and the remaining 2 were water days. On conditioning days, five rats were given grape juice and the remaining five rats were given milk. Five minutes after fluid presentation, the rats were injected intraperitoneally with apomorphine hydrochloride $(18 \mathrm{mg} / \mathrm{kg}$, mixed in sterile water $12 \mathrm{mg} / \mathrm{ml}$ ), and the fluids were removed after the rats stopped drinking, which invariably occurred within 2 min of injection. Posttests consisted of 2 consecutive days of two-bottle testing, executed as described above, and 2 days of single-bottle testing, given with grape juice and then milk, and with a water day preceding each flavor day.

\section{RESULTS}

All rats increased their intake of each flavor from the neophobia day to the single-bottle pretest day. Figure 1 presents the mean intakes of the CS fluids by the two groups in the single-bottle pretest and posttest in the two-bottle pretest and posttest (the intakes on the pairs of days were averaged together) and during acquisition. In the figure and in the material to follow, the amounts consumed by a group refer to the flavor used as the CS for that group.

In the single-bottle test, pretest intake of all milk rats (mean, $12.8 \mathrm{~g}$ ) was greater than intake of all grape juice rats $(8.2 \mathrm{~g})$; all rats decreased their intake from pretest to posttest, with all milk rats but one declining $(9.6 \mathrm{~g})$ more than all grape juice rats $(3.7 \mathrm{~g})(\mathrm{U}=1, \mathrm{p}<.01)$; in the posttest 